\section{Origin of Multiple Trunks Affects Crapemyrtle Posttransplant Establishment}

\author{
Michael A. Arnold
}

\section{AdDitional INDEX WORDS. \\ Lagerstroemia indica, landscape establishment, landscape maintenance, multistem shrubs, multitrunk trees, posttransplant establishment, tree mortality}

Summary. Bare-root 17.5-inch-tall $(44.45-\mathrm{cm})$ 'Sarah's Favorite' crapemyrtle (Lagerstroemia indica L.) liners were grown in \#3 [2.75-gal (10.4-L)] black plastic containers and trained to one, three, or five trunks by one of two methods. Half of the plants were established from multiple liners with each trained to form one of the trunks. The others were established by planting a single liner in each container, pruning them back to within 2 inches $(5.1 \mathrm{~cm})$ from the substrate surface, and then training elongating buds or adventitious shoots to the desired number of trunks. Once plants reached a marketable size they were transplanted to a landscape for two growing seasons to determine the effects of the treatments on trunk survival or growth uniformity in the landscape. The study was replicated in time with containerized 'Basham's Party Pink' crapemyrtle liners, but only grown in the field for 1 year. Growth and quality differences were minimal at the end of nursery production for either clone, thus favoring recommendation of whichever treatment would be most economical to produce the desired growth form. However, in the landscape phase, survival of 'Sarah's

Associate professor of landscape horticulture, Depart ment of Horticultural Sciences, Mail Stop 2133, Texas A\&M University, College Station, TX 77843-2133.

This project was funded in part by the Texas Agricultural Experiment Station and a grant from the Texas Ornamental Enhancement Endowment. The author wishes to thank Garry McDonald and Mitchell Goyne for their technical assistance. Mention of a trademark, proprietary product, or vendor does not constitute a guarantee or warranty of the product by the author, the Texas A\&M University, or the Texas Agricultural Experiment Station, and does not imply its approval to the exclusion of other products or vendors that also may be suitable.
Favorite' crapemyrtle and growth and uniformity of 'Basham's Party Pink' crapemyrtle were greater for several growth measures when multiple trunks were produced by training stems of the same plant as opposed to planting multiple liners. Trunk survival was generally good for three or fewer trunks, but significant losses often occurred when the planting units had five trunks, especially when grown from multiple liners. Growth and survival differences among treatments were more pronounced with increasing trunk number and the longer the planting units were in the field (landscape).

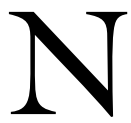

umerous species of multitrunk plants are produced each year by the nursery industry. Important examples include crapemyrtles (Lagerstroemia L.), waxmyrtles (Myrica L.), and birch trees (Betula L.) (Arnold, 2002; Dirr, 1998). In the past multitrunk plants were often produced by pinching back an established seedling or clone and then training released lateral buds to form several competing leaders. Pruning in nurseries is skilled labor intensive and expensive (Davidson et al., $2000)$. In response to these economic pressures, multitrunk plants are usually produced by planting several individual liners of a given taxa within the same container or adjacent to each other in planting holes during field production. These liners may be of seedling or clonal origin. Current practices are dictated principally upon economic considerations during production that may include: the cost of using multiple liners versus the labor costs associated with pruning and training multiple stems from a single liner, the marginal benefit in reduced rotation times, or improved plant quality associated with either practice (Whitcomb, 1988). Little consideration is given to the longer term consequences of such practices in landscape establishment.

Information on this topic is generally anecdotal, but considerable information exists in the forestry and ecology literature to suggest that interplant competition, even within the same species can result in differential survival rates (Kozlowski and Pallardy, 1997). Intracanopy competition among competing leaders as sinks for carbohydrates, hormones, and nutrients can determine branch survival, 
particularly in response to shading by competing portions of the same or adjacent canopies (Ford, 1992; Kozlowski and Pallardy, 1997). Survival of multiple liners is typically high under the low level of environmental stresses present in the nursery, but may not be so successful during the stress of posttransplant establishment or after longer-term competition among genotypes with different growth potentials. The limited research that has been conducted on this topic dealt with evergreen shrubs, japanese aucuba (Aucuba japonica Thunb.), waxleaf ligustrum (Ligustrum japonicum Thunb.), sandankwa viburnum (Viburnum suspensum Lindl.), and hetz juniper (Juniperus chinensis L. 'Hetzi'). This research has shown improvements in canopy quality in the nursery in response to use of multiple liners per container (Whitcomb, 1988; Whitcomb et al., 1975). Information on carry-over effects in the landscape are even more limited. Three replications each of waxleaf ligustrum and sandankwa viburnum and five replications of hetz juniper were transplanted to the landscape. Three years later there were no negative effects from the multiple liner treatments (Whitcomb, 1988). However, replication in these studies was low and the species tested were not grown as tree forms where the lose of a multistem character would be as deleterious to the appearance of the plants.

Investigation of this topic would allow nursery producers to determine whether these alternative production practices result in similar quality products during container production or in subsequent landscape plantings. If one method results in superior trees to the other, then an opportunity exists to differentiate a fairly generic product or identify the process resulting in a higher quality product. Professional landscapers and consumers would benefit from the data as an aide in product selection for superior landscape performance.

The overall objectives of this study were to compare container nursery and landscape establishment responses of crapemyrtles produced in containers via pruning and training of a single plant to a multitrunk habit versus planting of multiple liners in the same container to achieve a multitrunk unit. The null hypothesis is that there are no differences in the production methods.

\section{Materials and methods}

1998 Planting. Uniform 17.5inch-tall bare-root liners of 'Sarah's Favorite' (Schaefer Nursery, Winchester, Tenn.), a tree-form white flowering crapemyrtle, were planted on 1 Apr. 1998, into 60 \#3 containers (Lerio Corp., El Campo, Texas) filled with a 5 milled pine bark: 1 builders sand (by volume) substrate. The substrate was amended with $16 \mathrm{~N}-3.1 \mathrm{P}-10.0 \mathrm{~K}$ controlled release fertilizer (Southern Special; Scotts Corp., Marysville, Ohio) at the rate of $2 \mathrm{lb} / \operatorname{yard}^{3}\left(1.2 \mathrm{~kg} \cdot \mathrm{m}^{-3}\right)$ nitrogen, $1.5 \mathrm{lb} / \operatorname{yard}^{3}\left(0.89 \mathrm{~kg} \cdot \mathrm{m}^{-3}\right)$ of micromax micronutrients (Scotts Corp.), $6 \mathrm{lb} / \operatorname{yard}^{3}\left(3.6 \mathrm{~kg} \mathrm{~m} \mathrm{~m}^{-3}\right)$ of dolomitic lime (Vulcan Materials Co., Tarrant, Ala.), and $3 \mathrm{lb} /$ yard $^{3}$ (1.8 $\mathrm{kg} \cdot \mathrm{m}^{-3}$ ) of gypsum (Standard Gypsum Corp., Fredericksburg, Texas). Ten containers were planted with one liner each that was trained to a single leader. Ten of the containers were planted with three liners and another ten containers with five liners each. Each liner was pruned to a single leader. The remaining 30 containers were planted with a single plant per container. On 7 July 1998, the liners in these 30 containers were pruned back to within 2 inches of the substrate surface. Elongating buds or adventitious shoots arising from below the cut surface were trained to one, three, or five stems per plant replicated with ten containers for each treatment. Single stem trunks were trained vertically using $3 \mathrm{ft}(0.9$ m) bamboo stakes. Multiple trunks were trained in an equally spaced radiating pattern from the crown of the plant with trunks angled at about $20^{\circ}$ angles from vertical.

This created a two shoot origin by three trunk number factorial with ten replications per treatment. Plants were placed in a completely random design in an outdoor graveled container nursery in College Station, Texas, and grown until the majority of the plants reached a marketable size as defined by the ANLA standards (Amer. Nursery and Landscape Association, 1996). Daily fertigation to runoff was accomplished using a $\mathrm{N}$ rate of $50 \mathrm{ppm}(50$ $\mathrm{mg} \cdot \mathrm{L}^{-1}$ ) from a $24-8-16$ Peters water soluble fertilizer $(24 \mathrm{~N}-3.5 \mathrm{P}-13 \mathrm{~K}$, Scotts Corp.), with sulfuric acid (93.2\% $\mathrm{H}_{2} \mathrm{SO}_{4}$, Harcros Chemicals Inc., Kansas City, Mo.) injected into the irrigation stream to achieve a target $\mathrm{pH}$ of 6.5. An application of $50 \mathrm{ppm}$ che- lated iron (Sprint 138, CIBA-Geigy Corp., Greensboro, N.C.) was applied as a substrate drench on 31 July 1998.

Shoot length, trunk diameter at 6 inches $(15.2 \mathrm{~cm})$ above the substrate surface, and survival were assessed at the conclusion of production on 8 Oct. 1998. Trunk cross-sectional area was assessed on a container basis by summing the calculated cross-sectional areas for the individual stems. Uniformity of multiple trunks within a container was quantified by subtracting minimum from maximum shoot length and minimum from maximum trunk diameter to obtain the differential shoot lengths and differential trunk diameters for each container. The smaller the differential measurements the more uniform the trunks. Survival of individual trunks, or portions thereof if dieback was suspected, were determined by the presence of green leaves. If leaves were not present, live stem length was determined by visual detection of live cambial tissues when stems were lightly scratched.

Plants were transplanted on 8 Oct. 1998 , to a field site to assess landscape impacts of the production treatments. The soils on the site were Boonville Series, Boonville fine sandy loam, fine, montmorillic, thermic ruptic-vertic albaqualfs ( $\mathrm{pH} 8.7$, bulk density 1.51 $\mathrm{g} \cdot \mathrm{cm}^{-3}, 61 \%$ sand, $11 \%$ clay, $28 \%$ silt). Irrigation via $1 \mathrm{gal} / \mathrm{h}\left(3.8 \mathrm{~L} \cdot \mathrm{h}^{-1}\right)$ drip emitters was provided daily during the first week of establishment, then on alternate days for the next 3 weeks, and afterwards weekly during the growing season or more frequently as needed to avoid wilting during summer droughts. The 3 - $\mathrm{ft}$ stakes present in the nursery were replaced with 6 - $\mathrm{ft}(1.8-\mathrm{m})$ bamboo stakes. Individual trunks were trained to the stakes and suckers were removed at bimonthly intervals throughout the growing season. The same growth measures as described for the nursery phase were recorded in the field on 9 Nov. 1999, and 20 Oct. 2000.

1999 Planting. The 1999 study was designed to repeat the 1998 study with expanded replication to fifteen plants per treatment. The protocol for the study was the same with the following exceptions. 'Basham's Party Pink' crapemyrtle liners were transplanted on 13 Apr. 1999, to the six treatment combinations in \#3 containers filled with a 6 pine bark : 2 peat moss : 1 vermiculite : 1 hadite clay (by 

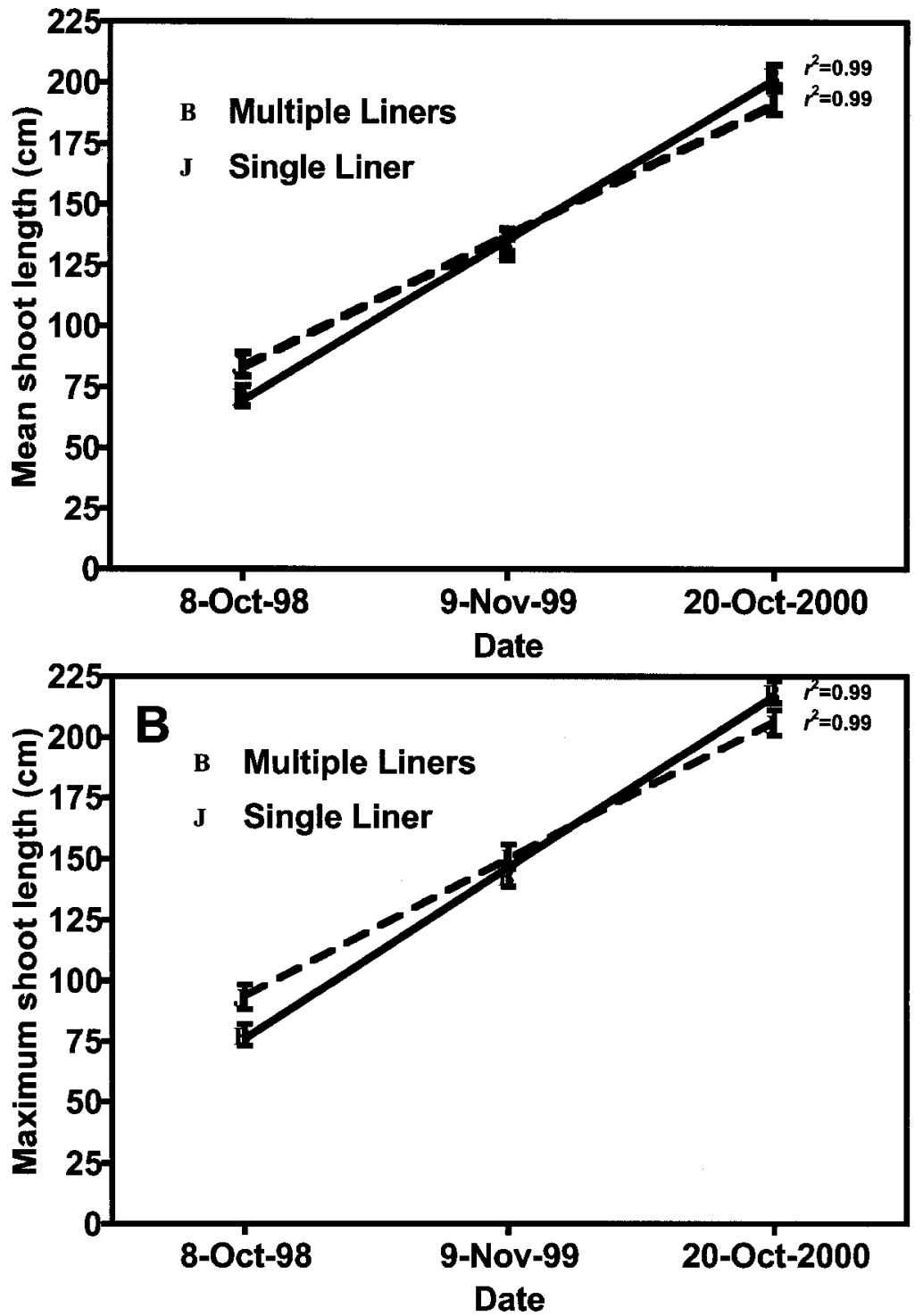

Fig. 1. Interactions for mean shoot length (A) and maximum shoot length per planted unit (B) among container-grown crapemyrtles trained to a multiple stem growth form by planting multiple liners per container or pruning to multiple stems on a single liner over time after transplanting to the landscape, 1998 planting. Individual values represent the mean ( \pm standard errors) of 30 observations. First-order polynomial equations represented in the figures were significant at $P \leq 0.05,1 \mathrm{~cm}=0.39$ inch.

volume) commercial substrate (Horticultural Products, Hope, Ark.) containing amendments as previously describe. Plants were transplanted to the field on 3 Aug. 1999, and field measurements were collected on $16 \mathrm{Nov}$. 1999 , and 20 Oct. 2000.

Data were analyzed separately for the plants transplanted in the 1998 and 1999 experiments. An analysis of variance was performed using the general linear models procedures in SAS (SAS Institute Inc., 1992) to determine the significance of interactions and main effects in each experiment. Significant $(\mathrm{P}<0.05)$ higher order interactions, and significant lower or- der interactions and main effects not involved in significant higher order interactions, were further analyzed using stepwise regression techniques.

\section{Results and discussion}

1998 Planting. Three way interactions among the origin of multiple trunks, the number of initial trunks planted, and time in the field were not statistically significant $(P \leq 0.05)$ for any of the measured or calculated growth parameters (data not presented). Significant interactions did occur among the origin of multiple trunks and time in the field (Fig. 1) and the number of initial trunks and time in the field (Fig. 2). Differences in plant growth due to the origin of multiple trunks were minimal at the end of nursery production on 8 Oct. 1998, compared to the effects of the number of trunks per planted unit (Fig. 2). Mean (Fig. 1A) and maximum (Fig. 1B) shootlength per planted unit was slightly greater for trunks derived from trained stems than those from multiple liners at planting to the field, whereas the reverse situation occurred at the end two subsequent seasons. However, from a commercial perspective these differences were likely inconsequential. Mean shoot length declined slightly with increasing trunk numbers per container across time, with the decline being more pronounced for the minimal shoot length per container (Fig. 3A).

Significant interactions where present between the number of initial trunks and the growth rates across origin of the multiple trunks over time (Fig. 2). Multiple trunks resulted in reduced diameter of the largest trunk per planted unit over time (Fig. 2A), and reductions in the size of the minimum trunk per planted unit was much more pronounced (Fig. 2B). These differences in growth rates were strongly reflected in the differential trunk diameter over time, where increasing the number of trunks per planted unit dramatically increased the variation between the largest and smallest trunk (Fig. 2C). While uniformity of trunk growth within a planted unit decreased over time with increasing number of trunks present on the planted unit, the total cross-sectional area of all trunks within the planted unit increased relatively uniformly from one to five initial trunks (Fig. 2D). This may represent a similar situation to coppicing in hardwood timber production. Coppicing species with a rapid growth and propensity for root or crown suckering are selected to increase the total biomass harvested at the expense of individual trunk diameter. Even with this objective, foresters regularly thin the number of trunks with intermediate harvests for other purposes from four, to two, to one trunk over time to enhance survival and uniformity of the final timber harvest (Zobel et al., 1987).

Probably the most significant finding from the 1998 planting was the interaction among the number of initial trunks and their origin on survival 
of the individual trunks (Fig. 3C). Across time in the field, survival of single trunk plants regardless of origin was high and similar, but as the number of initial trunks per planted unit increased the rate of expected survival of the individual trunks decreased more dramatically for those derived from multiple liners than those from trained stems (Fig. 3C). With three planted trunks, on average 2.9 trunks survived if they were trained from a single liner, while only 2.5 survived if they were from multiple liners. Practically, this translates to on average one out of ten three-trunk planting units missing a trunk if trained from a single liner compared to every other planting unit missing a trunk if derived from multiple liners. This could represent a decrease in the aesthetic value of the three trunk specimen. Survival differ- ences between trunks from trained stems or multiple liners was even more pronounced with five trunk units (Fig. 3C). In this case survival of trunks from trained stems was $97 \%$ while that from multiple liners was only $69 \%$. Although differences in survival of trunks at the end of production was nonsignificant (data not presented), field or landscape survival of 'Sarah's Favorite' crapemyrtle was significantly impacted by this production practice (Fig. 3C).

1999 Planting. Three way interactions among the origin of multiple trunks, the number of initial trunks planted, and time in the field were not statistically significant $(P \leq 0.05)$ for any of the measured or calculated growth parameters (data not presented). Differences at the end of container production on 3 Aug. 1999, due to the origin of multiple trunks (Fig. 4) were minimal in comparison to the effects of increasing the number of trunks (Fig. 5). At the end of production (3 Aug. 1999), the minimum trunk diameter and trunk cross-sectional area of multiple trunk planting units produced using liners were slightly greater than that of those produced from cut stems (Fig. 4). However after the second growing season in the field, minimum trunk diameters and trunk cross-sectional areas were $11 \%$ and $22 \%$ greater, respectively, with the trunks from cut stems than from multiple liners. As was seen in the 1998 plantings, the minimum trunk diameters for planting units with multiple trunks were smaller over time than with single trunks or fewer trunks (Fig. 5A), although the total crosssectional area per planted unit increased
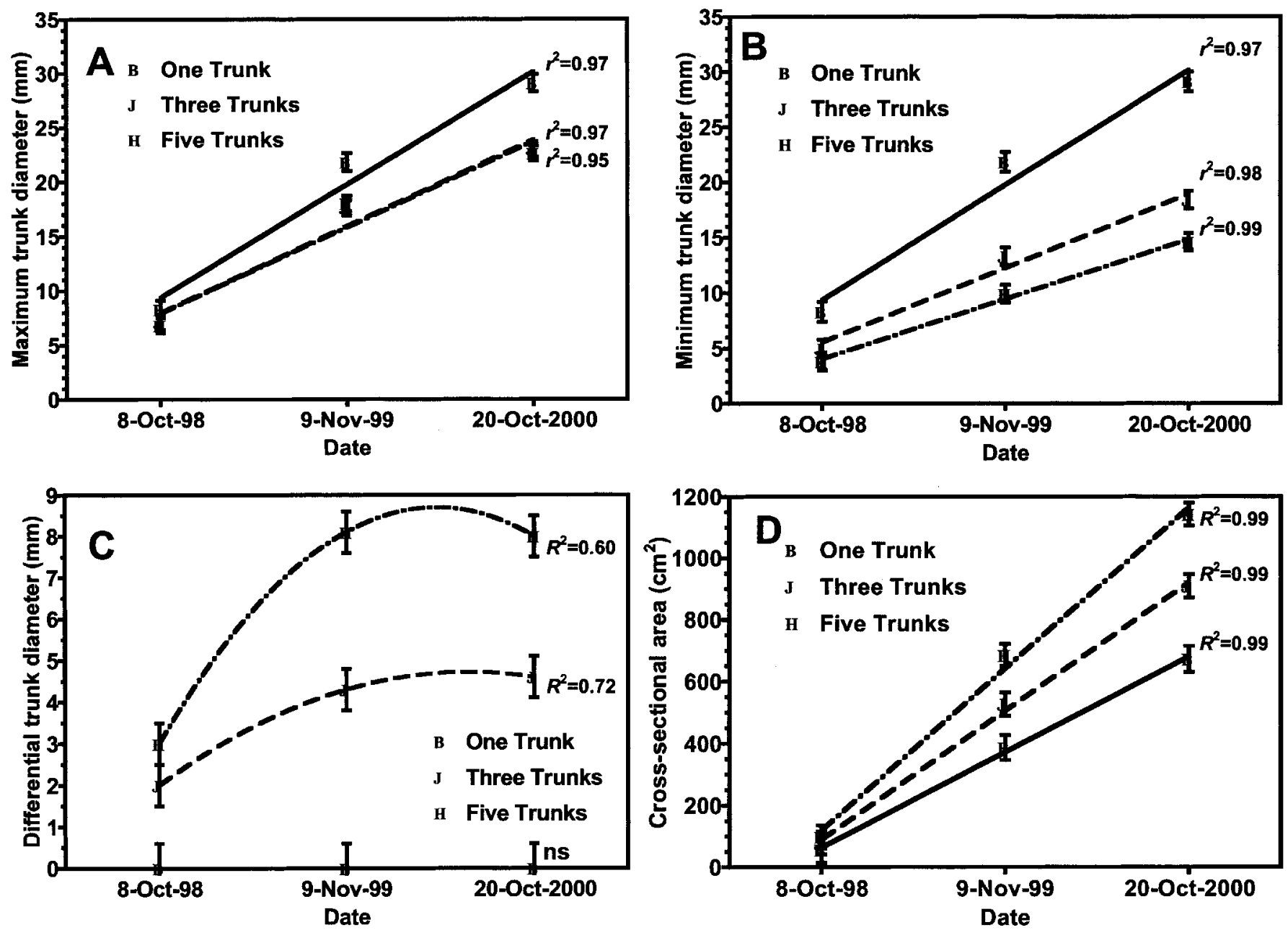

Fig. 2. Interactions for maximum trunk diameter (A), minimum trunk diameter (B), differential trunk diameter (C), and trunk cross-sectional area (D) per planted unit among container-grown crapemyrtles trained to one, three, or five initial trunks per container over time after transplanting to the landscape, 1998 planting. Individual values represent the mean ( \pm standard errors) of 20 observations. First and second order polynomial regression equations represented in the figures were significant at $P \leq 0.05$, unless indicated as $\mathrm{ns}=$ nonsignificant, $1 \mathrm{~mm}=0.04 \mathrm{inch}, 1 \mathrm{~cm}^{2}=0.16 \mathrm{inch}^{2}$. 

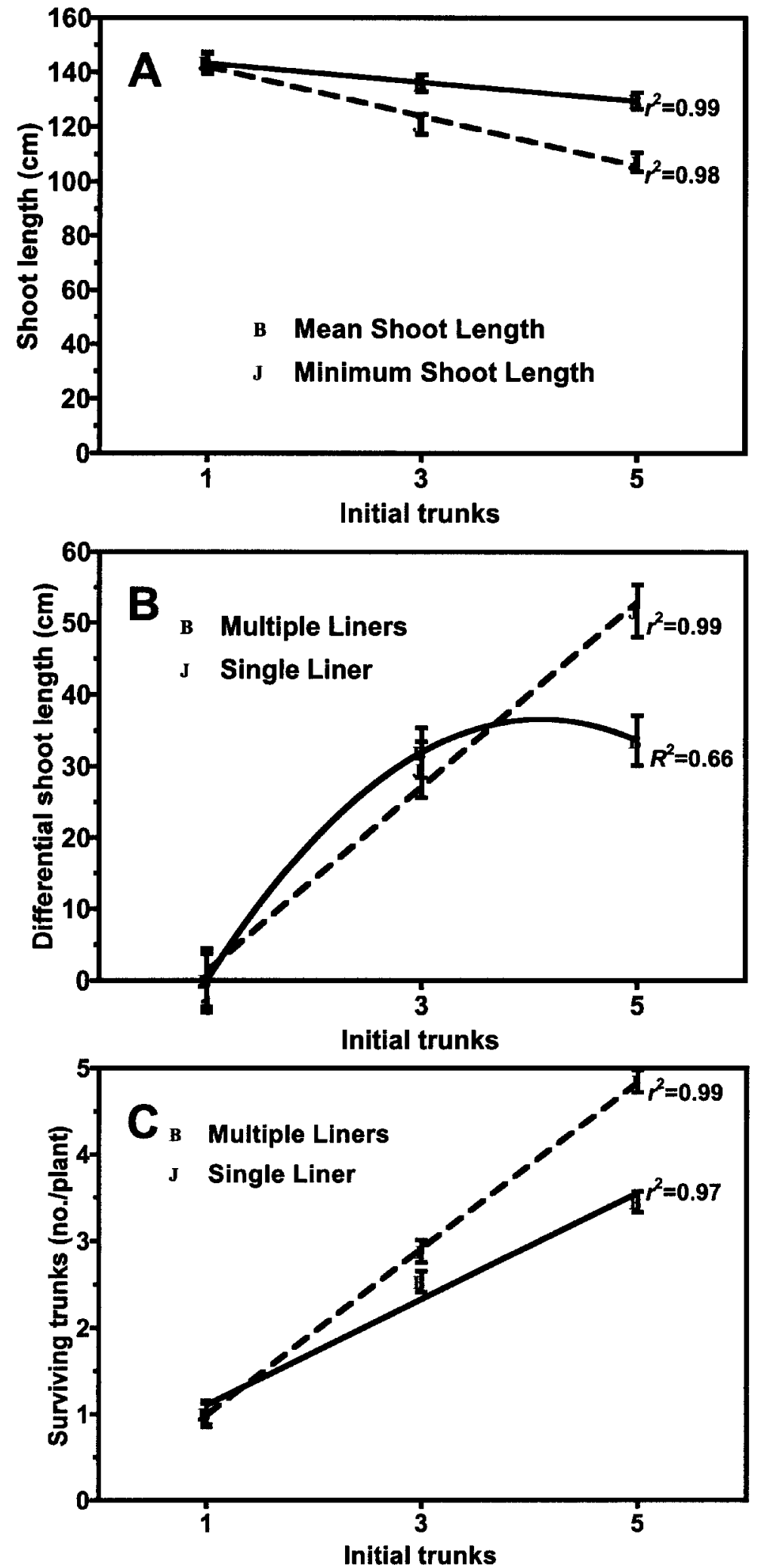

Fig. 3. Main effects after transplanting to the landscape, 1998 planting, of initial trunk number on mean shoot length (A) and minimum shoot length (A) per planted unit and interactions for differential shoot length $(B)$ and the number of surviving trunks per planted unit (C) among container-grown crapemyrtles trained to a multiple stem growth form by planting multiple liners per container or pruning multiple stems on a single liner. Individual values represent the mean ( \pm standard errors) of 60 observations for the main effects in $A$ and 30 for the interactions in $B$ and $C$. First and second order polynomial regression equations represented in the figures were significant at $P \leq 0.05,1 \mathrm{~cm}=0.39$ inch. with increasing number of initial trunks (Fig. 5B). This was consistent with the results seen in the 1998 planting. Across trunk origin, the survival rate of multiple trunks decreased over time (Fig. 5C). Survival during the first two growing seasons was mildly impacted with three initial trunks, but was rather poor when the number of initial trunks increased to five (Fig. 5C).

Mean and minimum shoot length declined consistently with increasing trunk number (Fig. 6A), while maximum shoot length per planted unit was affected slightly in 'Basham's Party Pink' crapemyrtle. Across trunk origin and time in the field, the differentials in trunk diameter increased with increasing numbers of initial trunks (Fig. 6B). Similarly, differentials in shoot growth increased with increasing numbers of trunks (Fig. 7A). Uniformity of shoot length among trunks was greater for trunks originating from trained stems than multiple liners (Fig. 7A). Trunk cross-sectional area was greater for trunks from trained stems compared to those from multiple liners, particularly at higher densities of trunks (Fig. 7B). In general, the effects of multiple liners compared to trained stems were not as pronounced with the 1999 plantings as with the 1998 plantings. This could be a differential cultivar response, or perhaps more likely the differences had not yet been fully expressed in the 1999 plantings considering that the responses related to trunk origin were more strongly expressed in the second growing season for the 1998 plantings than in the first season.

Few meaningful differences in growth or quality were found at the end of nursery production for either clone, thus favoring recommendation of whichever treatment would be most economical to produce the desired growth form. However, results from the landscape phase would suggest that the consumer or professional landscaper may not come to the same conclusion. Survival of 'Sarah's Favorite' crapemyrtle and growth and uniformity of 'Basham's Party Pink' crapemyrtle were greater for several growth measures when multiple trunks were produced by training stems of the same plant as opposed to planting multiple liners. Trunk survival was generally good for three or fewer trunks in most instances, but significant losses often occurred when the planting units 

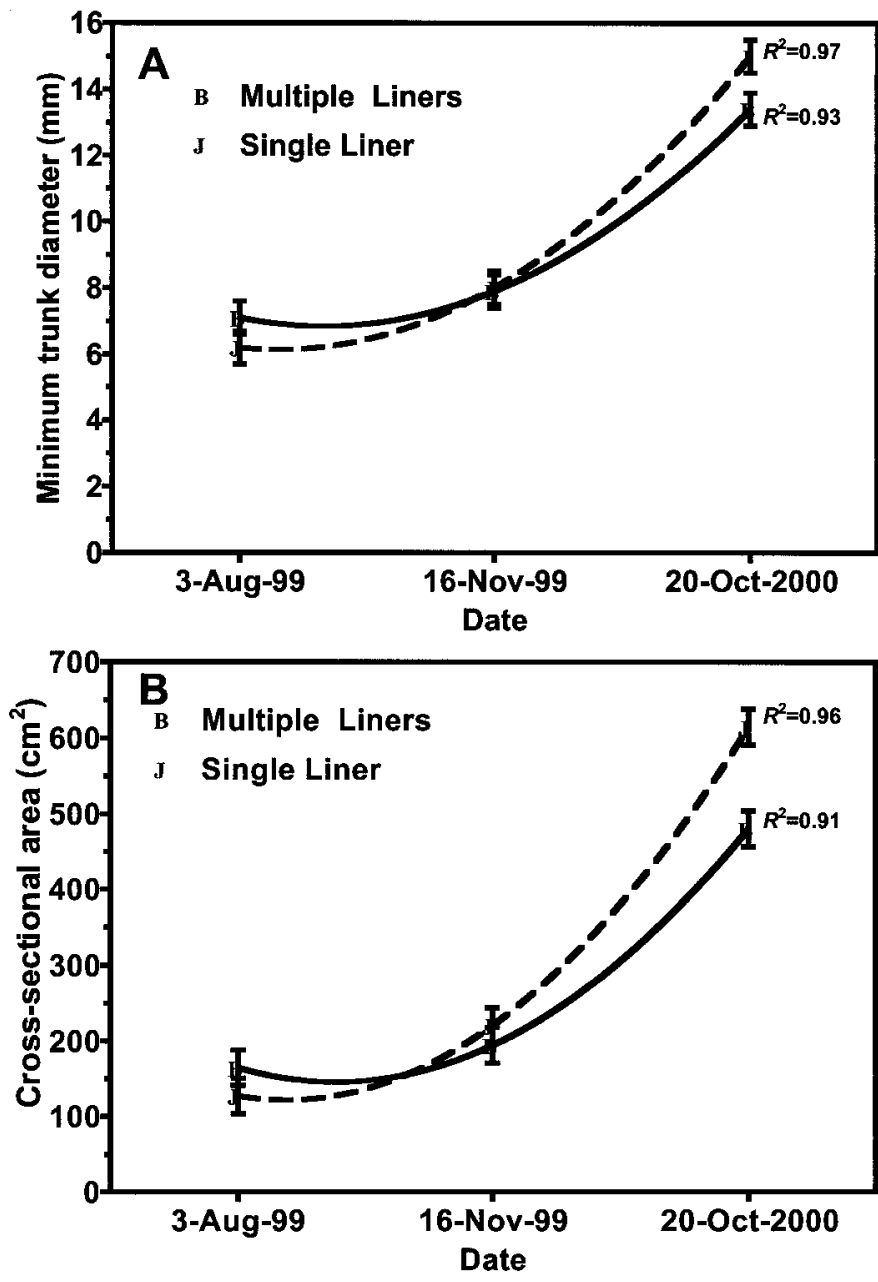

Fig. 4. Interactions for minimum trunk diameter (A) and trunk cross-sectional area (B) per planted unit among container-grown crapemyrtles trained to a multiple stem growth form by planting multiple liners per container or pruning multiple stems on a single liner over time after transplanting to the landscape, 1999 planting. Individual values represent the mean ( \pm standard errors) of 45 observations. Second order polynomial regression equations represented in the figures were significant at $\boldsymbol{P} \leq$ $0.05,1 \mathrm{~mm}=0.04$ inch, $1 \mathrm{~cm}^{2}=0.16$ inch $^{2}$.

had five trunks, especially when grown from multiple liners. This would suggest an optimum of three trunks per container for the clones tested in this study. This number of trunks is consistent with observations of foresters on eucalyptus (Eucalyptus Brut.) and other species used in coppice systems where four trunks are usually trained per stump. Growth and survival differences among treatments were more pronounced with increasing trunk number and the longer the planting units were in the field (landscape). This was in contrast to earlier reports by Whitcomb et al. (1975, 1988 ) indicating no adverse or even positive effects of multiple liners on the landscape performance of some evergreen shrubs. Studies are needed to determine the long term landscape impacts of these treatments under varied maintenance regimes and whether or not the results can be extrapolated to other species grown as multiple trunk trees.
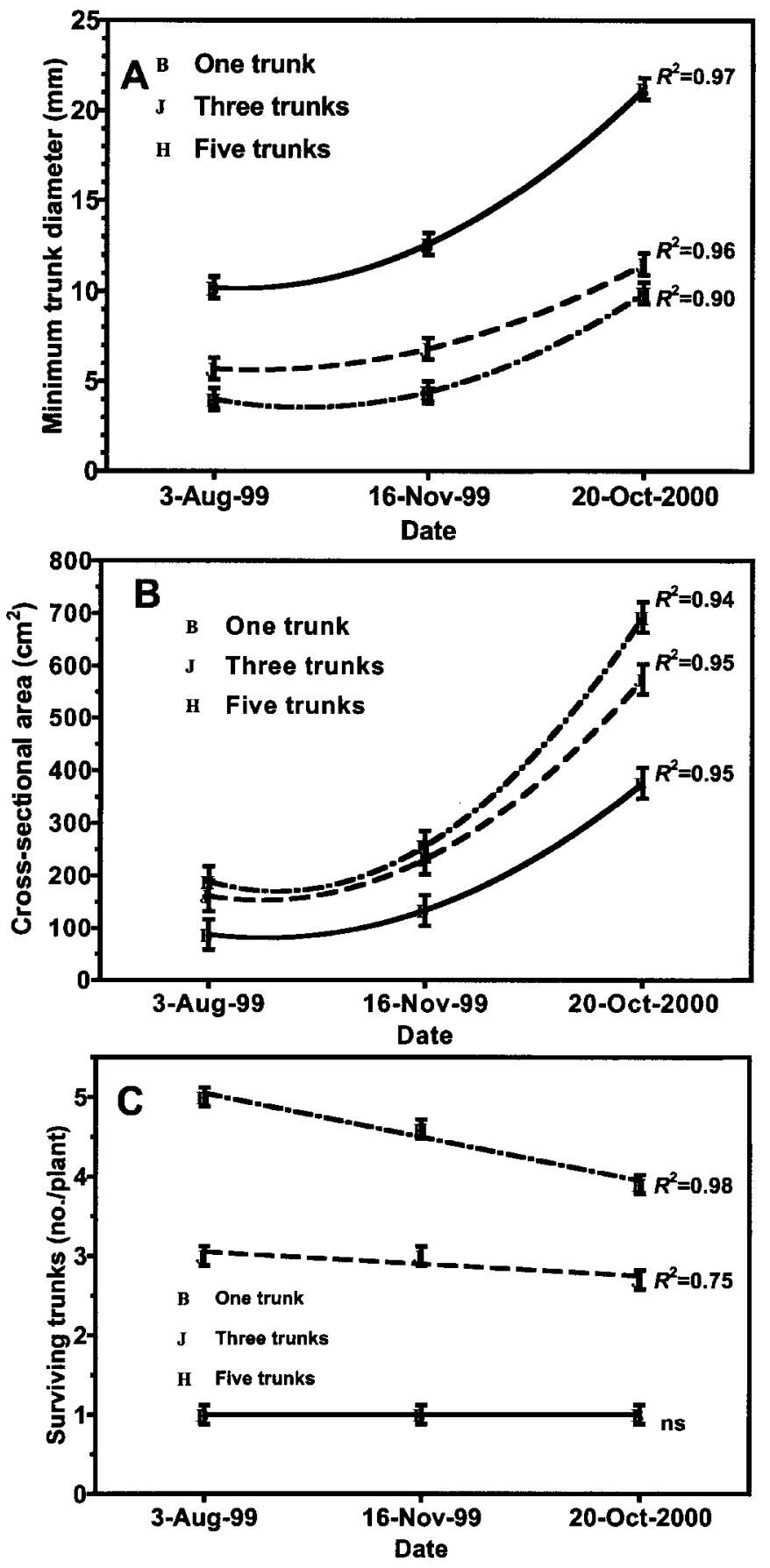

Fig. 5. Interactions for minimum trunk diameter (A), cross-sectional trunk area (B), and surviving trunks (C) per planted unit among container-grown crapemyrtles trained to one, three, or five initial trunks per container over time after transplanting to the landscape, 1999 planting. Individual values represent the mean ( \pm standard errors) of 30 observations. First and second order polynomial regression equations represented in the figures were significant at $\boldsymbol{P} \leq \mathbf{0 . 0 5}$, unless indicated as ns = nonsignificant, $1 \mathrm{~mm}=0.04 \mathrm{inch}, 1 \mathrm{~cm}^{2}=0.16 \mathrm{inch}^{2}$. 

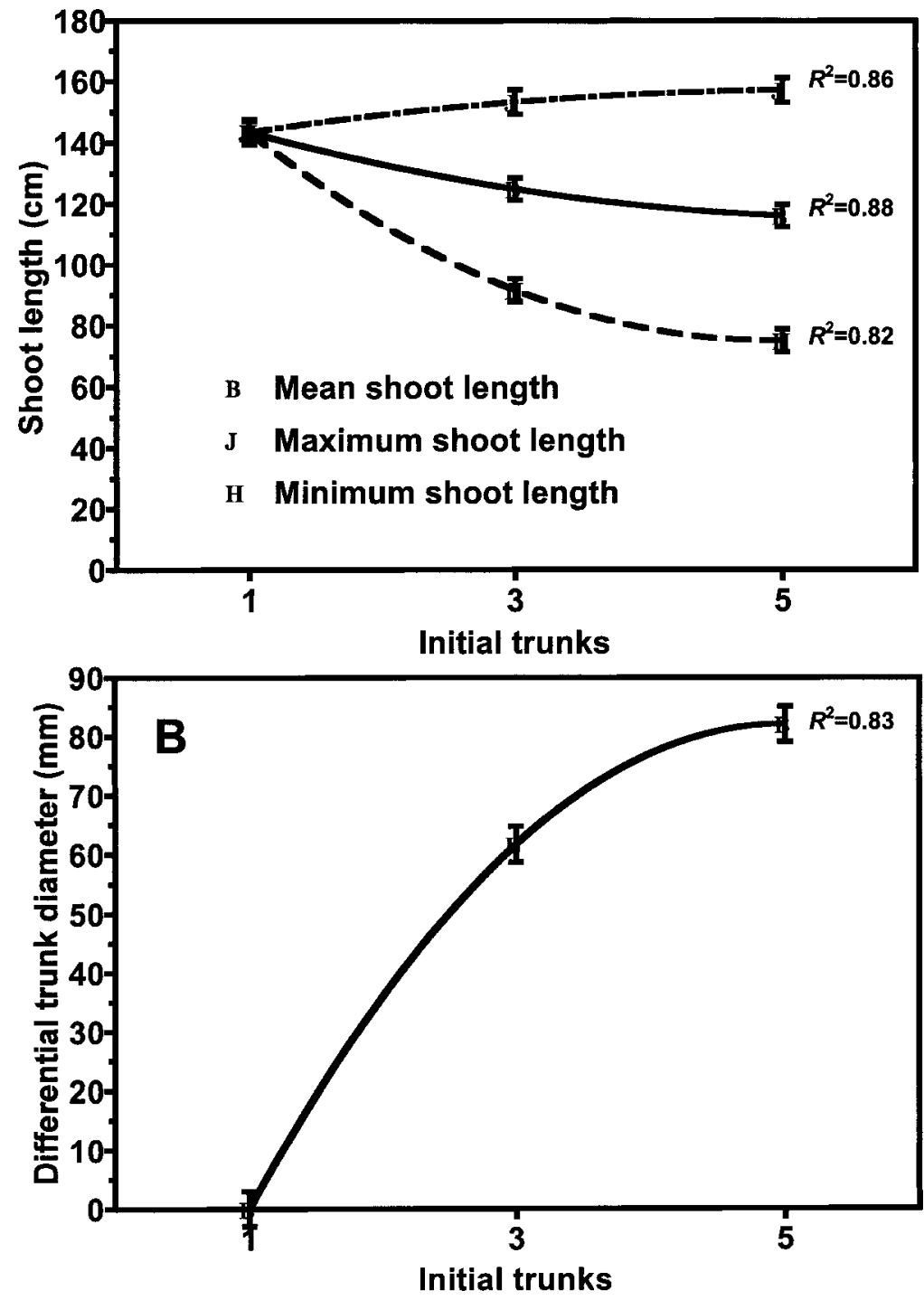

Fig. 6. Main effects of the number of initial trunks per planted unit on the mean, maxiumum, and minimum shoot length $(A)$ and differential trunk diameter $(B)$ on container-grown crapemyrtles trained to a multiple stem growth form and then transplanted to the landscape, 1999 planting. Individual values represent the mean $( \pm$ standard errors) of 90 observations. Second order polynomial regression equations represented in the figures were significant at $P$ $\leq 0.05,1 \mathrm{~cm}=10 \mathrm{~mm}=0.39$ inch.

\section{Literature cited}

American Nursery and Landscape Association. 1996. American standard for nursery stock. Amer. Nursery and Landscape Assn., Wash., D.C.

Arnold, M.A. 2002. Landscape plants for Texas and environs, 2nd ed. Stipes Publ. L.L.C., Champaign, Ill.

Davidson, H., R. Mecklenburg, and C. Peterson. 2000. Nursery management administration and culture. 4th ed. Prentice Hall, Upper Saddle River, N.J.
Dirr, M.A. 1998. Manual of woody landscape plants: Their identification, ornamental characteristics, culture, propagation and uses. 5th ed. Stipes Publ. L.L.C., Champaign, Ill.

Ford, E.D. 1992. The control of tree structure and productivity through the interaction of morphological development and physiological processes. Intl. J. Plant Sci. 153:S147-S162.

Kozlowski, T.T. and S.G. Pallardy. 1997. Growth control in woody plants. Academic Press, San Diego, Calif. 

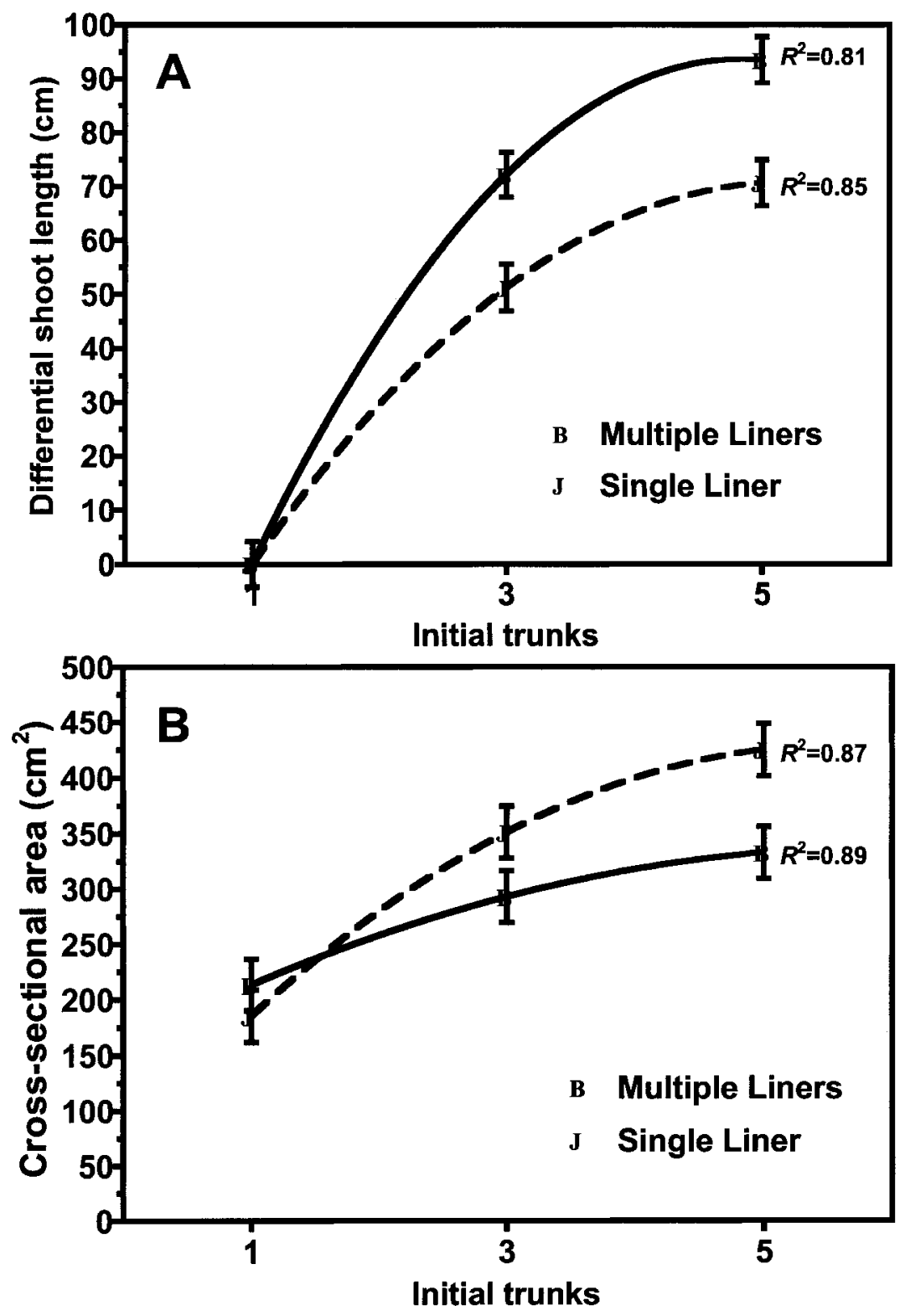

Fig. 7. Interactions for differential shoot length (A) and cross-sectional trunk diameter (B) per planted unit among container-grown crapemyrtles trained to a multiple stem growth form by planting multiple liners per container, or pruning multiple stems on a single liner, after transplanting to the landscape, 1999 planting. Individual values represent the mean ( \pm standard errors) of 45 observations. Second order polynomial regression equations represented in the figures were significant at $P \leq 0.05,1 \mathrm{~cm}=0.39 \mathrm{inch}, 1 \mathrm{~cm}^{2}=0.16 \mathrm{inch}^{2}$.

SAS Institute, Inc. 1992. SAS/STAT users guide. SAS Institute, Inc., Cary, N.C.

Whitcomb, C.E. 1988. Plant production in containers, revised. Lacebark Publ., Stillwater, Okla.

Whitcomb, C.E., J.G. Rackley, and R. Bean. 1975. The effects of multiple liners per container on growth and visual grade of woody ornamentals. Nursery Res. J. $3: 1-13$.

Zobel, B.J., G. van Wyr, and P. Stahl. 1987. Growing exotic forests. Wiley, New York. 